\title{
Evaluation of Retention Using Different Numbers and Position of Attachments with Mini Dental Implant Overdentures
}

Amanda McPherson Canizales

West Virginia University

Follow this and additional works at: https://researchrepository.wvu.edu/etd

\section{Recommended Citation}

Canizales, Amanda McPherson, "Evaluation of Retention Using Different Numbers and Position of Attachments with Mini Dental Implant Overdentures" (2011). Graduate Theses, Dissertations, and Problem Reports. 3270.

https://researchrepository.wvu.edu/etd/3270

This Thesis is protected by copyright and/or related rights. It has been brought to you by the The Research Repository @ WVU with permission from the rights-holder(s). You are free to use this Thesis in any way that is permitted by the copyright and related rights legislation that applies to your use. For other uses you must obtain permission from the rights-holder(s) directly, unless additional rights are indicated by a Creative Commons license in the record and/ or on the work itself. This Thesis has been accepted for inclusion in WVU Graduate Theses, Dissertations, and Problem Reports collection by an authorized administrator of The Research Repository @ WVU. For more information, please contact researchrepository@mail.wvu.edu. 
Evaluation of Retention Using Different Numbers and Position of Attachments with Mini Dental Implant Overdentures

Amanda McPherson Canizales, D.D.S.

Thesis submitted to the

\author{
School of Dentistry \\ At West Virginia University \\ in partial fulfillment of the requirements \\ for the degree of \\ Master of Science \\ In \\ Prosthodontics
}

Mike Bagby, D.D.S., PhD. (Chair)

Mark W. Richards, D.D.S., M.Ed.

Mohssen Ghalichebaf, D.D.S

Department of Restorative Dentistry

Morgantown, West Virginia

2011

Keywords: Mini Implants; Overdenture; Denture Retention 


\title{
ABSTRACT \\ Evaluation of Retention Using Different Numbers and Position of Attachments with Mini Dental Implant Overdentures
}

\author{
Amanda McPherson Canizales, D.D.S.
}

Objectives: To collect data for the retentive capabilities of mini dental implants in several numbers and positions when used with the mandibular overdenture; and compare that information to previous studies on the dislodging forces of locator attachments.

Methods: Acrylic blocks representing the mandibular arch and a mandibular denture were laboratory fabricated in high impact denture acrylic resin (Lucitone 199). Five mini implants were placed in the mandibular block and associated housings were picked up into the mandibular denture block using fast set acrylic (Super T). The denture block was then attached, via the same fast set acrylic, to an aluminium plate with a perpendicular screw for connection to the Instron Universal Testing Machine. Twenty pulls for each of the seven combinations of mini implants were recorded.

Results: Up to 20 tests for each group were recorded and the data was analyzed via Jump Software. The mean force to dislodgement for the seven groups were recorded in Newtons and are as follows: $1 \mathrm{MDI}-4.13,2 \mathrm{MDIs}$ narrow- 7.84, 2MDIs wide- 13.49, 3MDIs narrow-18.50, 3MDIs wide- 19.54, 4MDIs- 24.10, 5MDIs- 26.86.

Conclusions: Mini Dental Implant Overdentures are an acceptable alternative when traditional implants are not indicated. The data in this study leads to a recommended number of mandibular overdenture mini dental implants to be four, as five did not significantly increase the retention. Position affected the amount of retention only when using two mini dental implants, in which case a wide orientation was more retentive. 


\section{DEDICATION}

I would like to dedicate this project to my husband, Dr. Yeremi Canizales. You have given me so much love and encouragement over the last 10 years, and I am grateful to you for putting up with me! I know I would not be where I am today without having had you standing by my side. I am looking forward to the beautiful future we have planned together with the family we have been waiting for. I hope to spend the rest of our lives returning the love and support you have given me. 


\section{ACKNOWLEDGEMENTS}

I would like to thank the following people for changing and enhancing my life Professionally as well as personally:

Dr. Mike Bagby, Thank you so much for your diligence in working on this project. You were always the person who kept me moving forward and I would not have been able to do it without your guidance. It has been a great pleasure working with you and I will never forget all of your kindness.

Dr. Mark W. Richards, Thank you for providing me with the opportunity to study and learn more about dentistry that I could have ever imagined. Thank you for always being positive, helpful and enthusiastic about dentistry.

Dr. Mohssen Ghalichebaf, for the years of wisdom, guidance and meticulous training. I will take with me so many wonderful lesson from you about dentistry and life. 


\section{TABLE OF CONTENTS}

ABSTRACT

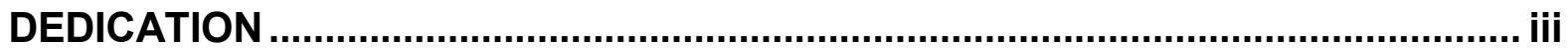

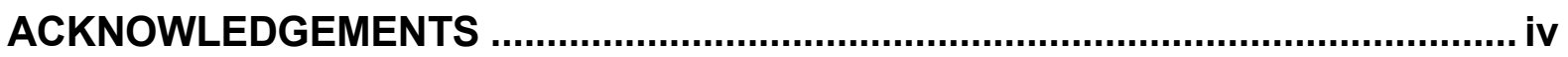

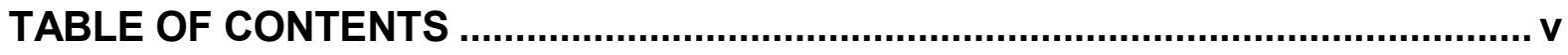

LIST OF TABLES

LIST OF FIGURES............................................................................................... vii

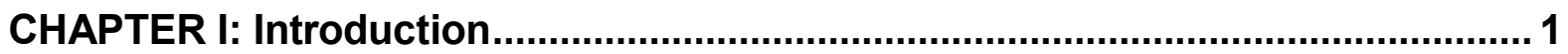

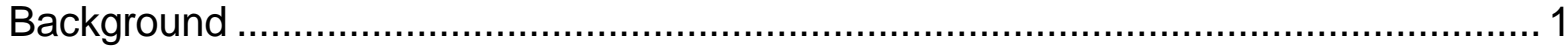

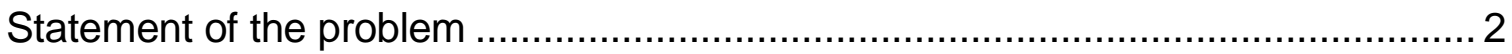

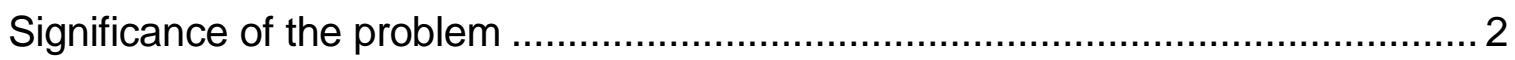

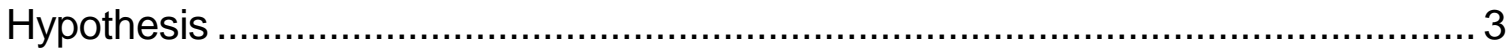

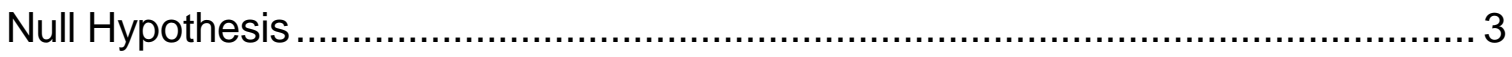

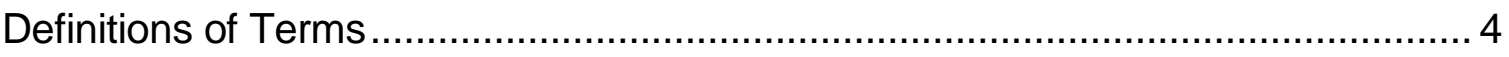

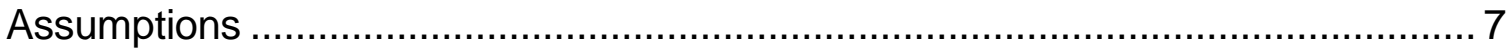

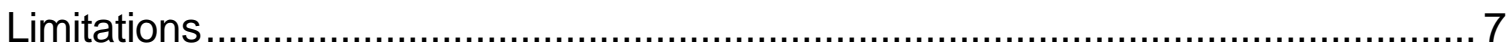

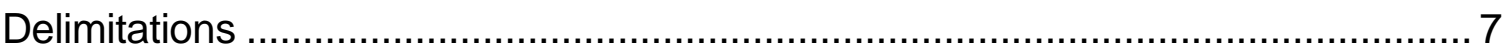

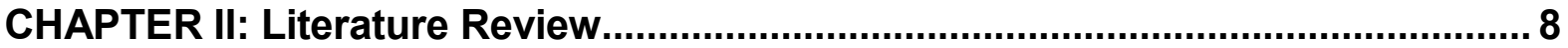

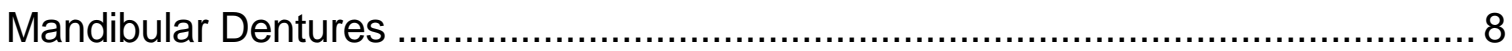

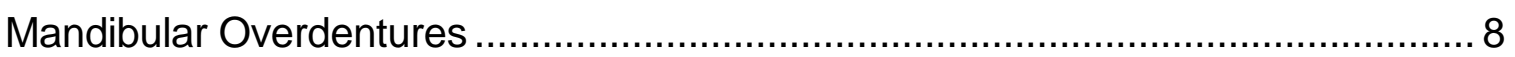

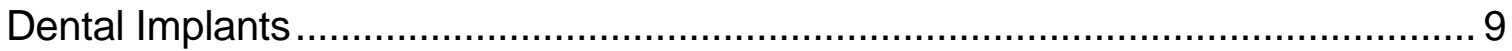

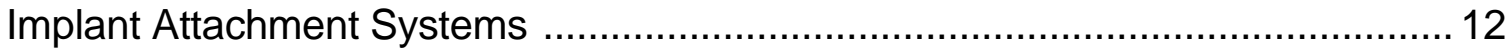

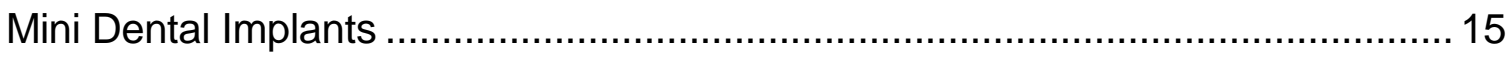

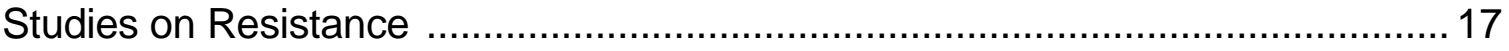

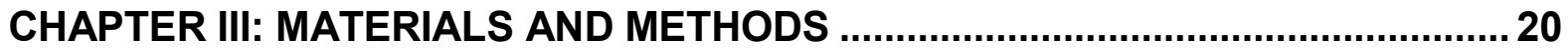

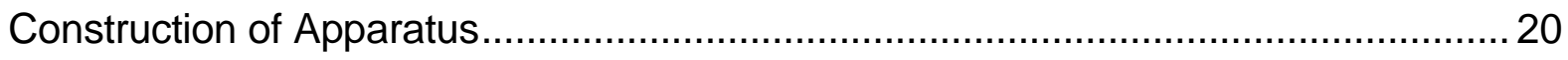

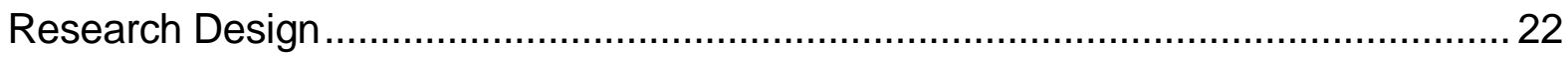

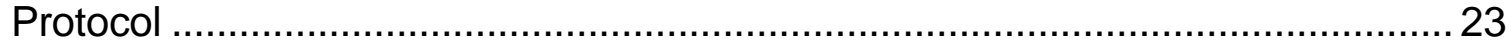




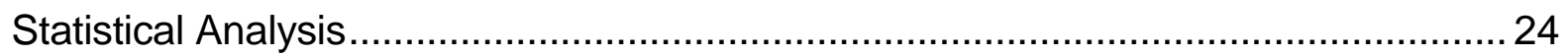

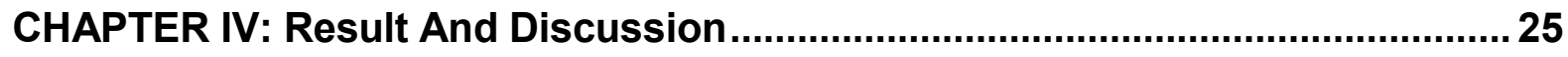

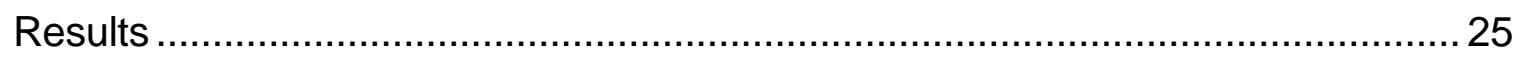

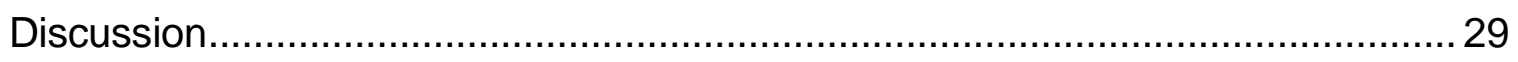

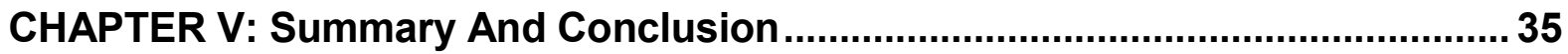

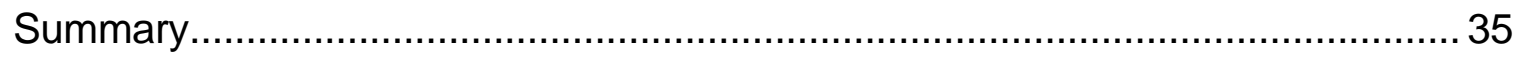

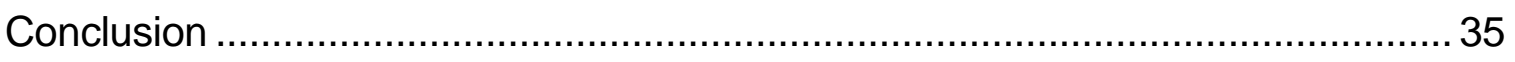

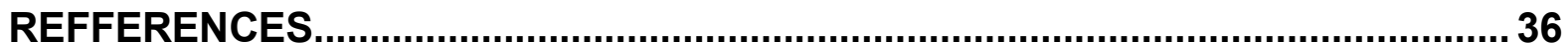

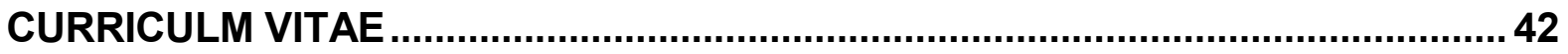




\section{LIST OF TABLES}

Table 1. Mean and Standard Deviation of Test Groups. ..................................... 25

Table 2. Summary of 2-way ANOVA for Dislodgement Force............................ 26

Table 3. Comparison of the Dislodgement Force for Each Group ..................... 27

Table 4. Summary of 2-way ANOVA for Average Load per Implant .................... 28

Table 5. Distribution of Force per Implant During Dislodgement ........................ 28

Table 6. Comparison for the Dislodgment Force per Implant ............................ 29

Table 7. Reported Forces from Load to Dislodgement Experiments for

Different Attachment Systems ........................................................................ 30 


\section{LIST OF FIGURES}

Figure 1. Construction of the Apparatus ........................................................ 21

Figure 2. Configuration of Testing Groups .................................................... 23

Figure 3.Instron Testing Machine .................................................................. 24

Figure 4. Mean Dislodging Force for Mini Implant Groups ................................ 26

Figure 5. Mini Implant Data as Compared to Zest Anchors International............ 32

Figure 6. Retention of Mini O-Rings and Locators as Reported by Authors....... 33 


\section{CHAPTER I}

\section{INTRODUCTION}

\section{BACKGROUND}

Traditionally, the mandibular complete denture has been the prosthesis that experiences the most difficulty due to dislodgment by the patients' floor of the mouth, tongue and buccal muscles. Because the palate provides a large area for the adhesion of saliva and denture base, along with the post palatal seal, the maxillary denture provides adequate retention in most circumstances even when ridge height is reduced. The mandibular denture, however, has the disadvantage of decreased surface area and an unreliable peripheral seal. Therefore, a mandibular denture must rely on the proper extension of the borders into the appropriate areas while avoiding overextension that allows the muscle attachments to dislodge the denture during function. This alone is a difficult balance to achieve; however, by adding the problems of poor bone height on the mandibular ridge, large tongues, mandibular defects, or poor lateral throat form, the mandibular denture becomes the most difficult prosthesis to achieve adequate retention for the patient during function.

Function can be improved by use of overdentures, when possible, by retaining roots of teeth to help maintain the bone level and give the patient more resistance to the dislodging forces. However, it does not correct all retention problems when used alone. The overdenture is highly dependent on patient selection. The patient must not only 
have retained the necessary abutment teeth needed, but must also demonstrate the ability to maintain these teeth.

It is increasingly becoming the gold standard to use dental implants with attachments to help retain the mandibular denture in patients with poor bone height and challenging anatomy (Saha, 2009). For these patients, two or more dental implants can be placed in the anterior mandible, and used with a variety of attachments that have components inside the denture base to give the denture more resistance to dislodging forces. Mini Dental Implants (MDl's) have been introduced that can greatly reduce the cost with minimal surgical intervention and can be an alternative to those who do not qualify anatomically for traditional diameter implants. MDl's provide a possible solution for the patient who cannot afford traditional dental implant therapy and have difficulty retaining the mandibular denture and is not a candidate for traditional implants due to lack of ridge height and width.

\section{Statement of problem}

Can the location and number of mini dental implants provide retention to the mandibular overdenture comparable to traditional implant systems?

\section{Significance of the Problem}

Although implants are not always required to maintain stability and resistance to dislodgement of the mandibular denture, there are many patients who benefit from the 
implant overdenture. These are the people who have long been edentulous and have lost ridge height and width, and in turn become increasingly unable achieve adequate function with a mandibular denture.

The consequences of edentulism without proper return of function include not only loss of esthetics and comfort, but negative effects on diet and nutrition and can contribute to the overall health of the patient. Some of the systemic comorbid factors that are associated with edentulism include hypertension, coronary artery disease, diabetes, neuropathy and dementia, arthritis, and even cancer (Felton, 2008).

Some of these consequences of edentulism can be positively impacted by the replacement of the missing teeth and return to a high level of function. It has been said that a complete denture can only return a patient to $30 \%$ of the function seen with natural teeth (Van Kampen, 2002). The use of dental implants can increase this masticatory function by allowing the patients to have better resistance to the dislodging forces, which help with chewing and digestion.

Due to the population growth in the US, combined with reduced access to dental care, researchers predict that the number of edentulous arches will continue to increase, despite reports that suggest edentulism decreased 6\% between 1988 and 2002. The incidence of edentulism in the United States has been highly associated with low income and low education levels (Felton, 2008). The high cost of traditional implant systems causes this treatment modality to be out of reach for many of the people who would benefit otherwise from implant overdentures. The increased use of mini dental implants could help provide another treatment option for those patients who cannot 
finance the placement of traditional implants, or who do not have the anatomical parameters needed for the placement of larger implants without additional procedures.

No studies currently exist to compare the mini dental implants' retention of mandibular overdentures in relationship to the traditional systems, nor how many small diameter implants are required to achieve a comparable measure of retention.

\section{Hypothesis}

Due to the smaller cuff heights and diameter of the o-rings used with small diameter implants, it is expected that more implants will be necessary to achieve acceptable resistance to displacement of the mandibular overdenture. It is also hypothesized that by increasing the number of mini implants to four or five, the retention could be equivalent to the current standard of two locator attachments, regardless of location between the mental foramina.

\section{Null Hypothesis}

The position of the implants will not have an effect on the dislodging forces when the same number of implants are compared. 


\section{Definition of Terms}

1. Retention- that quality inherent in the dental prosthesis acting to resist the forces of dislodgment along the path of placement (GPT, 2008).

2. Stability- the quality of a removable dental prosthesis to be firm, steady, or constant, to resist displacement by functional horizontal or rotational stress (GPT, 2008).

3. Overdenture- any removable dental prosthesis that covers and rests on one or more remaining natural teeth, the roots of natural teeth, and/or dental implants; a dental prosthesis that covers and is partially supported by natural teeth, natural tooth roots, and/or dental implants (GPT, 2008).

4. Dental Implant- a prosthetic device made of alloplastic material(s) implanted into the oral tissues beneath the mucosal or/and periosteal layer, and on/or within the bone to provide retention and support for a fixed or removable dental prosthesis (GPT, 2008).

5. Dental Implant System- dental implant components that are designed to mate together. An implant system can represent a specific concept, inventor, or patent. It consists of the necessary parts and instruments to complete the implant placement and abutment components (GPT, 2008).

6. Mini Dental Implant- a root form implant that has a size ranging from $1.8 \mathrm{~mm}$ to slightly above $2.0 \mathrm{~mm}$ (Christenson, 2006).

7. Abutment-1: that part of a structure that directly receives thrust or pressure; an anchorage 2: a tooth, a portion of a tooth, or that portion of a dental implant that serves to support and/or retain a prosthesis (GPT, 2008). 
8. Locator- a resilient stud attachment used for single dental implants with a fabricated metal female abutment and a male housing which retains a plastic retention cap that can have varying degrees of retention.

9. Attachment- 1: a mechanical device for the fixation, retention, and stabilization of a prosthesis 2 . A retainer consisting of a metal receptacle and a closely fitting part; the former (the female [matrix] component) is usually contained within the normal or expanded contours of the crown of the abutment tooth (or implant) and the latter (the male [patrix] component), is attached to a pontic or the denture framework (GPT, 2008).

10. Osseointegration-1: the apparent direct attachment or connection of osseous tissue to an inert, alloplastic material without intervening connective tissue 2: the process and resultant apparent direct connection of an exogenous materials' surface and the host bone tissues, without intervening fibrous connective tissue present 3: the interface between alloplastic materials and bone (GPT, 2008).

11. Torque- a twisting or rotary force. The movement of a system of forces producing rotation. Torque is measured in Newton centimeters $(\mathrm{Ncm})$ (GPT, 2008).

12. Immediate Loading- introduction of forces on dental implants immediately after implant placement (GPT, 2008).

13. Initial Stability- deals with the resistance to micromotion after implant placement, which can be affected by surgical technique, implant design and bone quality (Turkyilmaz, 2008).

14. Platform- the part of the implant body on which the abutment is set (Misch, 2005) 


\section{Assumptions}

1. It is assumed that locator attachments by Zest Anchors International are currently the most used attachment in dentistry.

2. The rigid fixation of the implants in acrylic with set screws is assumed to simulate osseointegration of the implants in bone.

\section{Limitations}

Limitations in this research include variations in the construction of the denture block with housing and the possibility of human errors.

\section{Delimitations}

1. The lack of a locator system being tested within the same parameters at the same time for comparison.

2. The calibration of the Instron Mechanical Testing Machine.

3. The necessity of balancing the load of the machine in between samples.

4. Lack of lubrication within the system which would exist in vivo. 


\section{CHAPTER II}

\section{LITERATURE REVIEW}

\section{Mandibular Dentures}

The mandibular denture's resistance to dislodgement has long been the cause of patients' trouble with mastication and speech (Rahn 121-29). Despite the proper construction of a mandibular denture, there are several factors that can contribute to continued lack of retention (Misch 1-17). The most common cause of a poorly retained mandibular denture is the patients' lack of bone height, usually due to an extended time of edentulism and denture wear (Pietrokovski, 2003). The lack of buccal ridge height diminishes the primary load bearing area and causes easy removal of the denture by the tongue and cheeks despite adequate seal created by a proper border molding technique. Other factors that can cause this lack of retention are a large, uncontrollable tongue and mandibular defects caused by traumatic extraction of teeth or resection of the mandible due to cancer.

\section{Mandibular Overdentures}

Treatment planning for mandibular overdentures when a patient is approaching edentulism can greatly improve the retention of the mandibular ridge height, and therefore the retention of the mandibular denture by preserving the load bearing areas 
(Rahn, 493-512). It also allows the patient to maintain proprioception, which can in turn prevent excessive forces on the ridge by the dentures causing rapid ridge resorption (Rahn, 493-512). Many of the patients who can benefit from the construction of an overdenture, however, have poor abutment teeth, or may not be able to maintain the desired abutment teeth. When indicated, dental implants can be utilized in these patients who would benefit from an overdenture, but no longer have the necessary abutment teeth available or are unable to maintain overdenture teeth (Naert, 2004). A study by Fiore et all in 2008 revealed that practitioners continue to prefer the retention of teeth for use with mandibular overdentures; however, as the prosthetic and endodontic complexities of the clinical situation increase, dentists were more inclined to recommend the replacement of overdenture teeth with implants in order to facilitate the retention of a mandibular denture.

\section{History of Dental Implants}

Dental implants can be defined as a substance that is placed into and/or upon the jaw bone to support a fixed or removable dental prosthesis. The portion of an implant that provides support for the dental implant abutment(s) through adaptation upon (eposteal), within (endosteal), or through (transosteal) the bone. Although dental implants may be classified by their silhouette or geometrical form (i.e., fin, screw, cylinder, blade, basket, root form, etc.), generally dental implants are classified based on their anchorage component as it relates to the bone that provides support and 
stability. Thus, there are three basic types of dental implants: eposteal dental implants, endosteal dental implants, and transosteal dental implants.

Dental implants have not always been in the form in which we see and use them today. The original use of dental implants appears to date back to the Mayan civilization in 600 A.D. where tooth-shaped pieces of shell were found to be replacing missing mandibular incisors in the skull of a twenty year old Mayan woman (Misch 3242). Although much debate transpired about whether or not the shells had been placed before or after death, in 1970 using radiography, Brazilian professor Amadeo Bobbio found that compact bone formation had occurred around the "implants," proving that they were utilized while the woman was alive. These were, therefore, the earliest know endosseous implants known to have been placed in a human. Many different forms of implants have been known to be used throughout the history of dentistry and fabricated from many different materials (Fagan 3-9). The major types of implants that were used clinically throughout the mid $19^{\text {th }}$ century were constructed mostly out of Vitallium and include the superiosteal implant, and two endosseous implants: the blade implant and the core implant.

The subperiosteal dental implant came about in the 1940's after being introduced by Gustav Dahl and were later placed successfully by Gershkoff and Goldberg. These were fabricated for the completely edentulous patient by first performing a surgery to expose the mandibular bone and to take an impression. This impression was used to fabricate a custom implant that would sit on the bone below the periosteum that had abutment posts extending from the frame to connect with a prosthesis. The subperiosteal implant could also be modified for partially edentulous patients (Fagan 
139-61). These implants and other soft-tissue-anchored implants are not longer used and have been shown to cause inflammation, infection, fistulas, and implant mobility (Zwerger, Abu-Id, and Kreusch 359-62).

Endosseous implants are defined by Fagan as "a substitute tooth root that is inserted into accommodating bone of sufficient height and width that has a protruding abutment post through the gingiva upon which a crown can be placed," (Fagan 61-71). The blade type implant was developed in hopes of distributing the forces of alveolar stress as compared to the wedge shaped implant. This implant design however, did not prove to be very conservative for the bone tissue because of its large size and invasive surgical procedure. The other type of endosseous dental implant, known as the core implant, was the precursor of what has developed into the modern dental implant. With its root like shape and conservative surgical procedure, the core implant has been modified and developed into a successful prosthesis with predictable results (Fagan 61 71).

It was in 1952 that Per-Ingvr Brånemark discovered that titanium would allow bone to grow in close approximation, thus marking the beginning of implant dentistry as it is known today (Misch 32-42). Brånemark believed that his work with the newly discovered biocompatible metal would be most easily accessible for clinical observations in the mouth. The first titanium dental implant in a human volunteer was placed in Sweden in 1965, and in 1978 Brånemark started a commercial partnership with the Swedish defense company, Bofors AB, later to become known as Nobel Biocare. His research in the application of dental implants with the company Nobel 
Biocare has defined the parameters for implant placement including speeds of drills, ideal temperatures to prevent bone necrosis and torquing considerations.

With the introduction of titanium as a material for dental implants, Nobel Biocare became the pioneer in the research and development of implant dentistry. Today over 150 dental implant companies exist, and along with Nobel, some of the leading companies include Zimmer Dental, 3i, BioHorizon, and Straumann.

\section{Dental Implant Attachment Systems}

Mandibular implant overdentures have been shown to be significantly preferred by patients over conventional dentures (Allen 2006) and the use of implant retained overdentures for patients suffering from diminished ridge height and poor retention of the mandibular denture is becoming the gold standard (Saha, 2003). Literature supports that implant supported ovedentures when used in the mandible meet the needs of patients by facilitating retention, stability, function and esthetics with predictable results, patient satisfaction and with a success rate upwards of $95 \%$ (Dounkoulakis, 2003).

The implant overdenture can be utilized with many different varieties of attachments to connect the mandibular denture to the implant. These attachments are securely coupled with the implant via a platform that has an anti-rotational feature such as a Morse taper or internal/external hex and an implant screw. The attachments can be individual as in locators or ball attachments, or connected with milled or cast bars 
that have retentive plastic or metal clips to provide coupling of the bar to the intaglio surface of the denture. Implants can be placed in a wide array of numbers and positions for denture retention depending on the discretion of the clinician and patient (Misch, 206-27).

The disadvantages of traditional implants include a prolonged healing time of up to 4-6 months, strict bone height and width requirements that may dictate bone grafting procedures (Misch, 105-29), and the space that is required for the attachments and housings. Contraindications for implant placement can apply to patients who are medically compromised and therefore unable to undergo surgery or have a disease which will in any way prevent bone healing after placement (Misch, 18-31)..

The surgery for dental implants consists of a flap incision to expose the bone and the preparation of an osteotomy site by a series of progressively larger drills. Once the osteotomy is prepared slightly smaller than the diameter of the implant, the implant is torqued into place and the area is then sutured and allowed to heal (Block, 3-33). The cost of dental implant placement, which can range from $\$ 1000$ to $\$ 2000$, is one of the major disadvantages and why many patients who would benefit from dental implants do not receive them. The success rates of implants is relatively high, but decreases in patients who smoke and have systemic diseases affecting healing, such as diabetes and forms of immunosuppresion (Misch, 18-31).

Implant attachments can improve a patient's experience with mandibular overdentures in many ways. Function is a major concern when considering a removable prosthesis and this can be evaluated by examining the bite force for patients 
who wear these prostheses. In 2011, de Freitas Borges et al examined mastication and nutrition in patients who had implants placed and immediately loaded. By recording a pre surgical baseline measurement and then recording bite force at 3 and 6 months post operative, they observed that after 6 months of using an implant retained overdenture patients were able to significantly increase their chewing efficiency. Several patients who were considered malnourished before the conversion of the prosthesis to the overdenture were able to increase their bite force in order to bring themselves into the nourished category (de Freitas Borges, 2011). This increase in bite force and chewing efficiency has been shown to maintain over time as seen by a study by van der Bilt et al. According to their study, not only did bite force significantly increase with an implant retained overdenture, but the bite force was unaltered after a 10 year period (van der Bilt, 2010).

The traditional implant overdenture has a myriad of attachment possibilities. The attachment of choice depends on many parameters, and implants can be restored with attachments independent of each other or splinted by the use of a bar. Some of the most commonly used and tested types of attachments include ball attachments, stud attachments, magnets and locators. In addition to being considered the attachment with the least complications, the milled or cast bar has been shown to be a very retentive attachment that gives the practitioner control when implants are not properly aligned (Klemetti, 2008). This treatment option, however, is much more expensive than individual attachments and requires more interocclusal space (Svetize, 2004). Patient satisfaction, regardless of attachment system, is greatly improved by the conversion of 
a traditional mandibular denture into an implant retained overdenture and remains so for the majority of patients for several years after fabrication (Al-Zubeidi, 2010).

Another factor that may affect an implant attachments system's retention is the distance between implants. In a study by Doukas et al in 2008, they found that interimplant distance only played a significant role when looking at retention with a Hader bar and the corresponding red and yellow clips. Another study by Michelinakis et al in 2006 agreed with the Doukas study in that significant differences were seen with interimplant distance when looking at Hader bars and red clips. In addition, the research showed that ball attachments showed superiority compared with all other attachment at $29 \mathrm{~mm}$ 's, whereas at $19 \mathrm{~mm}$ and $23 \mathrm{~mm}$ ball attachments were significantly more retentive than all other attachments except the red Hader bar clips (Michelinakis, 2006).

\section{Mini Dental Implant s}

The mini dental implant (MDI) is generally thought of as a root form implant that is less than $3 \mathrm{~mm}$ in diameter. The primary difference between traditional implants and MDl's is their small diameter does not allow for platform switching; and therefore, they are one piece with the abutment incorporated into the implant body. The controversy associated with mini dental implants is twofold in that 1) their small diameter increases their chance for fracture $($ Allum,2006) and 2) due to their one piece assembly, they are loaded immediately after placement by picking up the housings intraorally and allowing the denture to be attached to the denture when the patient leaves the office the same 
day as the surgery (Nazarian 110,112). This is a concern because it places forces on the implants before osseointegration has occurred (Ahn, 367-72). With immediate loading, a certain amount of primary stability is required to be able to safely load the implant and not cause failure of osseointegration (Dilek, 2007). However, a study by Balkin et all in 2001 showed histologically that immediately loaded mini implants not only appeared to be osseointegrated but that after 4 months the bone appeared to be mature and healthy.

One of the advantages of MDl's include the minimally invasive surgical technique, which does not require the preparation of an osteotomy site and uses hand torque drivers. The placement consists of using a pilot drill to pierce the gingival and make a guiding notch in the cortical bone. The implant is then positioned in the notch and the implant driver is used to drive the implant down until resistance is met. The final step is using the wing driver to finishing driving the implant until the collar is at the level of the tissue. The lack of osteotomy site preparation allows for the MDI to obtain a greater primary stability, therefore allowing the implants to be loaded sooner, and most times immediately (Dile, 2007).

Because of the smaller heights of the attachments, the space requirements for mini dental implants are not as demanding as with traditional implant systems. The major advantage of the MDI system, however, is the significantly lower cost at which the provider can place the implants and the housings. This lower cost can allow greater access to implant overdentures which provide increased resistance to dislodging forces for patients who otherwise would have extreme difficulty retaining their lower denture (Griffitts, 2005). One study by Preoteasa et al evaluated the decision making factors 
when using mini dental implants to retain overdentures. They reported that the average number of MDl's used in the mandible was 4.6 and that over $70 \%$ of the implants placed were $13 \mathrm{~mm}$ in length and $2.4 \mathrm{~mm}$ in diameter, the other $30 \%$ being of smaller length and diameter. They conclude that MDI overdentures can be an alternative to conventional implant overdentuers, and advantages of the system include smaller diameter, variable length, and o-ring retention system, which can be adapted more easily in certain edentulous conditions (Preoteasa, 2010). They report these conclusions without any information measuring the MDl's capability to provide adequate retention to the mandibular overdenture.

Bulard reported in 2005 a failure rate of $8.83 \%$ in a study of 1,029 MDl's at 5 months to 8 years in vivo showing that these systems can be used for long term retention and stabilization of prosthesis with success. Another study, which included 2,514 MDl's with a follow up of 2.9 years, revealed an overall implant success rate of 94.2\% (Shatkin, 2007). Some discussion as to whether mini dental implants should be splinted for use with mandibular overdentures in order to reduce marginal bone loss and presented; however, in a study by Jofre et al, it was concluded that there was no difference in marginal bone loss when using mini dental implants as ball attachments or when splinting MDl's with a bar.

\section{Studies on Resistance}

Many studies have been done on resistance to dislodging forces of implant overdenture attachments for traditional implant systems. These studies have compared 
the various implant systems to each other or the different types of implants attachments such as balls, bar and clip, ERA, magnets, etc. In order to investigate these parameters, the researchers used an approximate speed of the movement of the denture away from the ridge during mastication, which has been reported as $50.8 \mathrm{~mm} /$ minute. The most common instrument used to replicate the horizontal separation of the denture from the mouth is an Instron materials testing machine (Chung, 2004).

These articles report various information about the attachment forces for vertically directed dislodgment when implants are used to retain a mandibular overdenture. One of the most commonly researched attachment types is the $2.25 \mathrm{~mm}$ diameter Nobel Biocare ball which has had reports of dislodging forces from as little as $2.4 \mathrm{~N}$ up to $17.8 \mathrm{~N}$ (Petropoulos, 2002). When comparing the multiple types of attachments it is seen that dislodging forces can be as little as $1.25 \mathrm{~N}$ (as reported for the Zest magnet by Petropoulous et al) all the way up to $37.2 \mathrm{~N}$ (as reported for the Zest Anchor Advanced Generation by Petropoulos/Smith). It has been suggested that retention strengths from 5 to $7 \mathrm{~N}$ should be sufficient to stabilize mandibular overdentures (Pigozzo, 2009), however manufacturers report much higher dislodging forces of their components (Zest Anchors International).

According to authors Petropoulos and Smith, the most retentive attachment type is the bar and clip attachment, followed by the Sterngold ERA attachments, Zest Anchor attachments, ball attachments (Nobel Biocare $2.25 \mathrm{~mm}$ ) and Zest magnets in order of descending retention ranging from 20.6 Newton's to 1.25 Newton's (Petropoulos, 
1997). It is their suggestion that due to this variation, the clinician can control the amount of retention that is needed for each individual patient (Petropoulos, 2002). 


\section{CHAPTER III}

\section{Materials and methods}

\section{Construction of the Apparatus}

An acrylic block was constructed to represent the mandible and parallel holes were prepared at a 90 degree angle to the base with a $2.0 \mathrm{~mm}$ drill to serve as the osteotomy sites for the mini implants( Figure 1-A). The $2.1 \mathrm{~mm}$ diameter implants were then torqued into the acrylic and engaged. To confirm implant stability, set screws were placed from a facial approach and tightened (Figure 1-B). An acrylic block was also fabricated to represent the mandibular overdenture with the sites to hold the appropriate attachment housings to simulate the denture. The housings with o-rings were engaged onto the prosthetic head of the implant, and wax was used to block out the undercuts (Figure 1-C). An opening was made into the denture block so as to allow the housings to fit passively through with no contact in order for them to be picked up (Figure 1-D). Petroleum jelly was used in order to prevent the acrylic resin of the mandibular block from bonding to the acrylic used to engage the housings in the denture block. Autopolymerizing fast set acrylic was mixed and flowed around the housings and shaped in order to attach the denture to the Instron Machine (Figure 1-E).

Next, an aluminum plate with the size of the area of the denture block with the housing, and a center hole, was obtained. A $3 \mathrm{~mm}$ screw was threaded through the 
center hole in the aluminum plate. Acrylic was then used to secure the aluminum plate to the acrylic denture block at a 90 degree angle to the mandibular block and centered over the midline (Figure 1-F) a. The mandibular block/denture block apparatus with the screw was placed in a drill press and the angle of the screw was adjusted with the end of a dental surveyor to be perpendicular to the table. The assembly was moved to the Instron vice, while keeping the screw perpendicular to the table, and acrylic was added to the mandibular block to partially cover the top of the vice and ensure that the base was stable and its position was constant when the assembly was removed between implant set ups.

\section{Figure 1- Construction of Apparatus}

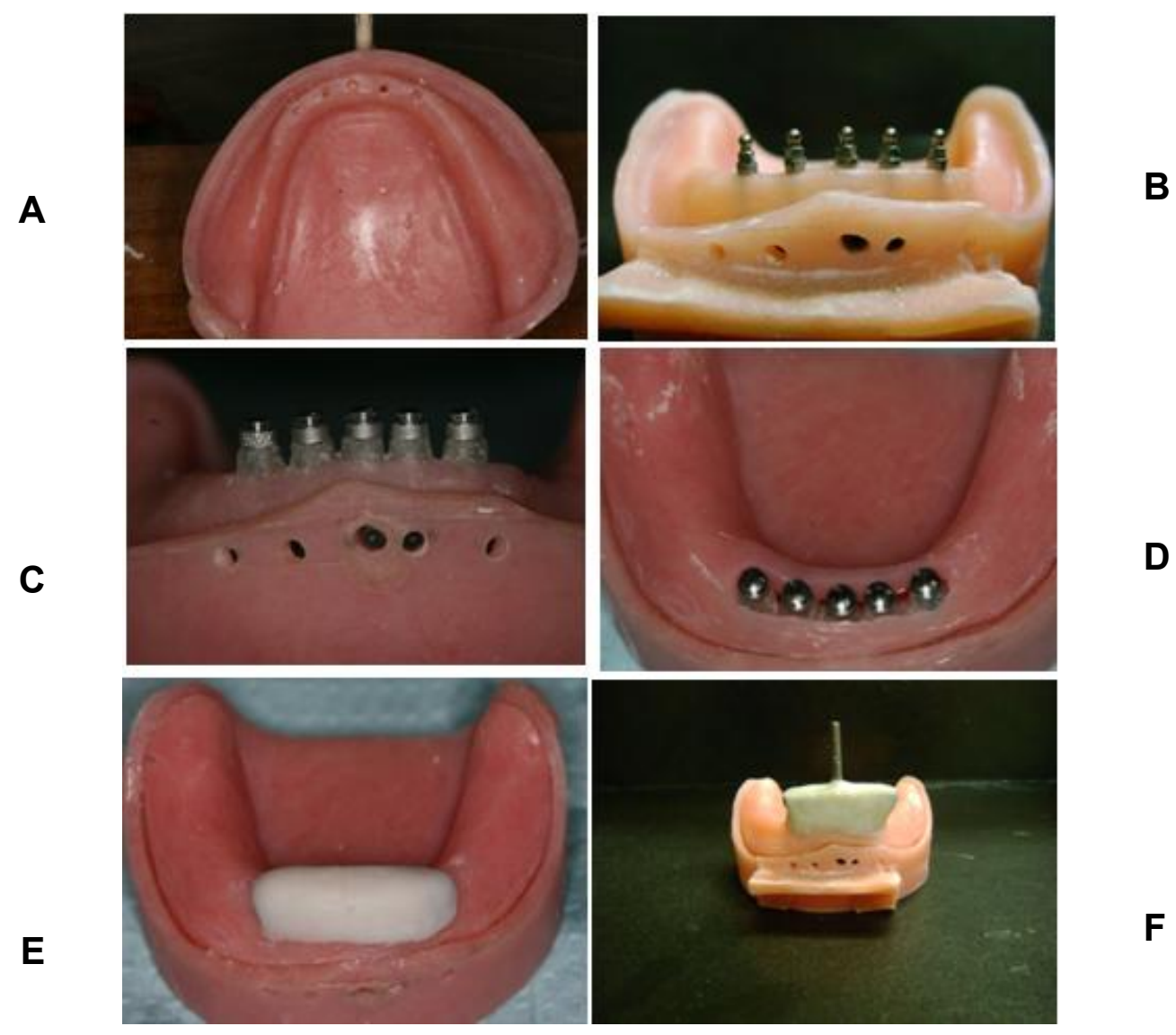




\section{Research Design}

The seven following combinations were tested by engaging the ball attachment with o-rings in the corresponding housings:

1. 1 IMTEC MDI Collared O-ball head implant at the midline Figure 2-A).

2. 2 IMTEC MDI Collared O-ball head implants in the area of the canines (Figure 2-B).

3. 2 IMTEC MDI Collard O-ball head implants in the area of the laterals (Figure 2-C).

4. 3 IMTEC MDI Collard O-ball head implants at the midline and in the lateral incisor region (Figure 2-D).

5. 3 IMTEC MDI Collared O-ball head implants, one at the midline and the other two in the canine region (Figure 2-E).

6. 4 IMTEC MDI Collared O-ball head implants (all but the midline) (Figure 2-F).

7. 5 IMTEC MDI Collared O-ball head implants (Figure 2-G). 


\section{Figure 2- Configuration of Testing Groups}
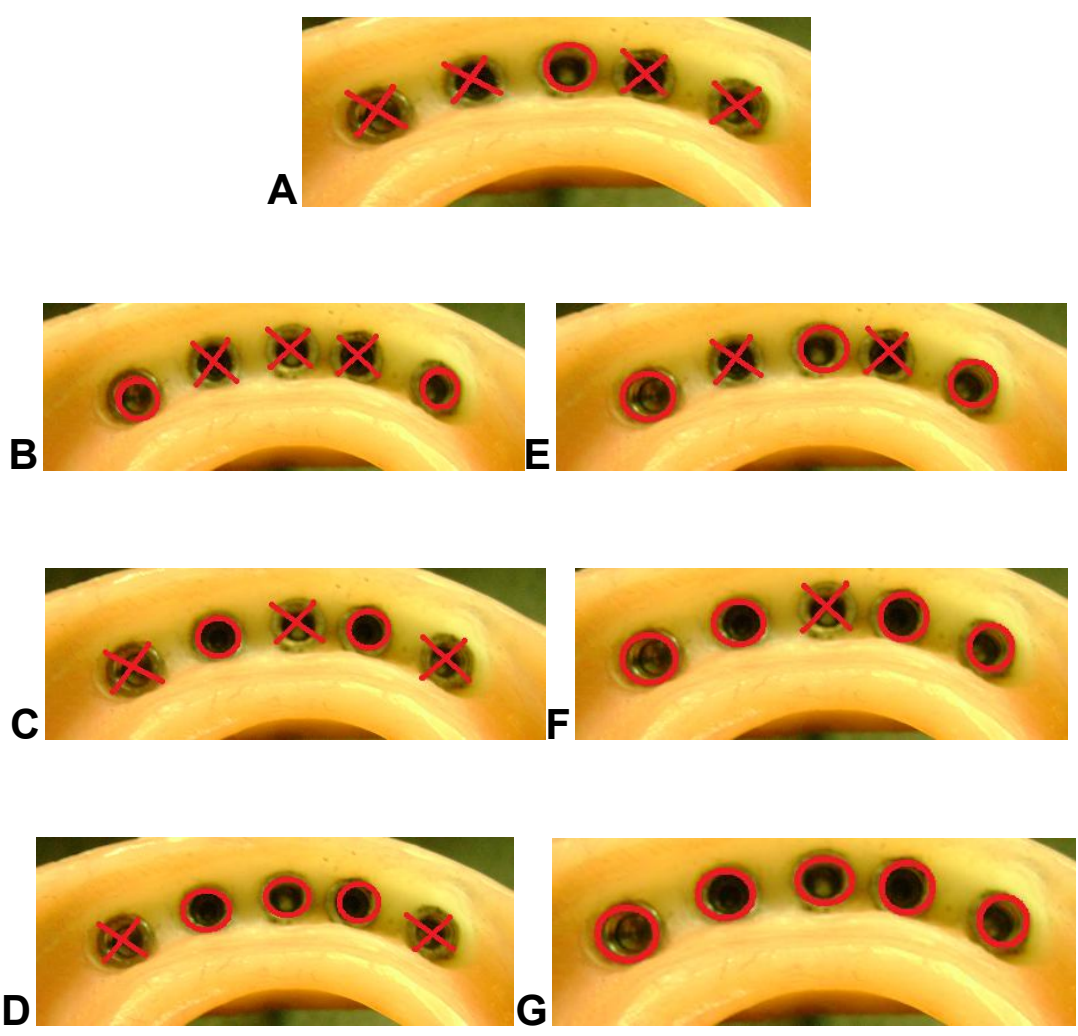

\section{Protocol}

This study was designed to use an Instron mechanical testing machine which is commonly used to test the mechanical properties of materials. The Instron Machine (Figure 3-A) was connected to the overdenture assembly (Figure 3-B). The mandible and denture blocks were separated at a recommended crosshead speed of $50 \mathrm{~mm} / \mathrm{min}$ (Chung, 2004). The force to dislodge the denture from the mini dental implant attachments was recorded up to 20 times for each implant combination. 
Due to an electrical failure of the testing machine during our testing, only 9 samples were taken for the 2 mini wide group. Because of the consistency of the recordings in that group, it was decided to include the group in the data set.

\section{Figure 3- Instron Testing Machine}

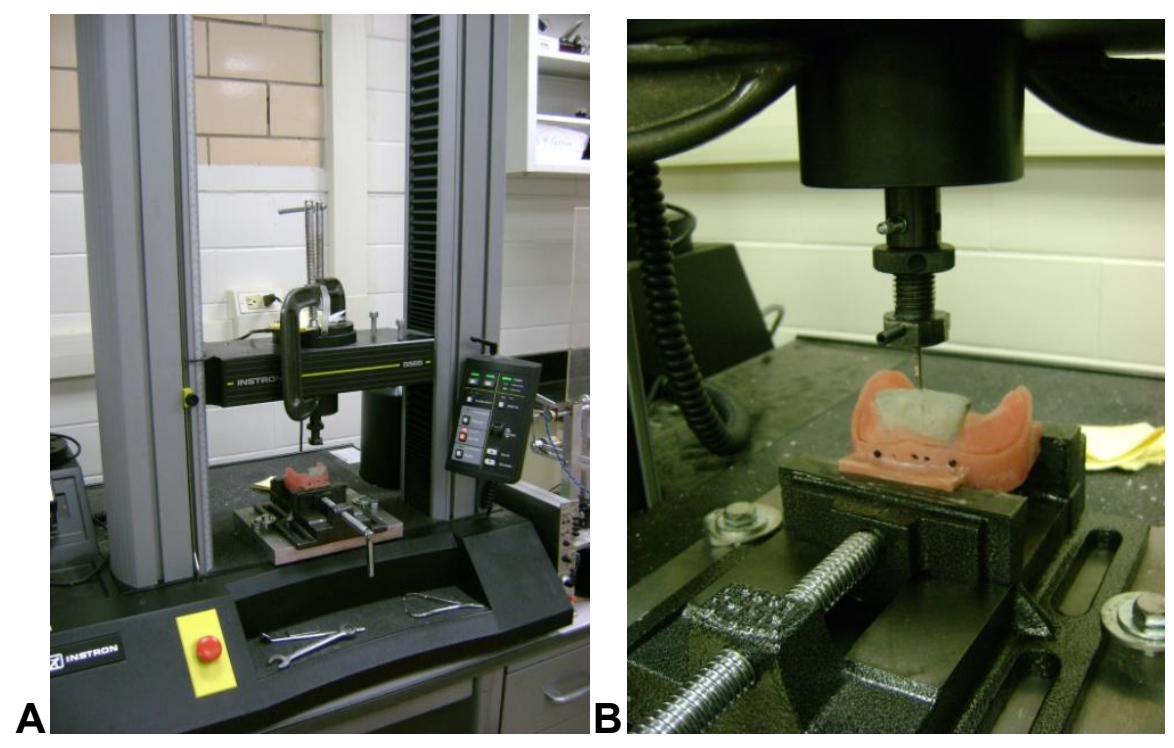

\section{Statistical Analysis}

The statistical analysis was accomplished by an ANOVA testing along with a Tukey-Kramer HSD from the data of average load to separate the assembly and using Jump Software. 


\section{CHAPTER IV}

\section{Results}

The loads were recorded for each of the seven combinations and the data was compared for the groups individually and as a whole. For the 5 mini group, 19 recordings were taken with a mean of 26.86 Newtons and the mean of the 20 recordings for the 4 mini group was 24.10 Newtons. The mean for the 20 recordings in the 3 mini wide and the 3 mini narrow groups varied slightly, with 19.54 and 18.50 respectively. 19 recordings for the 2 mini wide group revealed a mean of 13.49 Newtons, which had a significant difference with the 2 mini narrow group having a mean of 7.84 with the 9 recordings taken. Finally the 1 mini group had a mean of 4.13 Newtons for the 20 recordings. These values can be seen along with the standard deviations in Table 1 and displayed in Figure 4.

TABLE 1- Mean and Standard Deviation of Test Groups

$\begin{array}{cccc}\text { Name } & \text { Mean } & \text { Std Dev } & \text { N } \\ \text { 1 Mini } & 4.13 & 0.148 & 20 \\ \text { 2 Mini's Narrow } & 7.84 & 0.235 & 9 \\ \text { 2 Mini's Wide } & 13.49 & 1.262 & 20 \\ \text { 3 Mini's Narrow } & 18.5 & 0.348 & 19 \\ \text { 3 Mini's Wide } & 19.54 & 0.205 & 20 \\ \text { 4 Mini's } & 24.1 & 0.327 & 20 \\ \text { 5 Mini's } & 26.86 & 1.227 & 19 \\ & 25 & & \end{array}$


An analysis of variance compared the seven data as a whole. The $F$ ratio was $<0.0001$ as seen in Table 2. This ANOVA test shows that the means of our seven groups are not equal.

Figure 4- Mean Dislodging Force for Mini Implant Groups

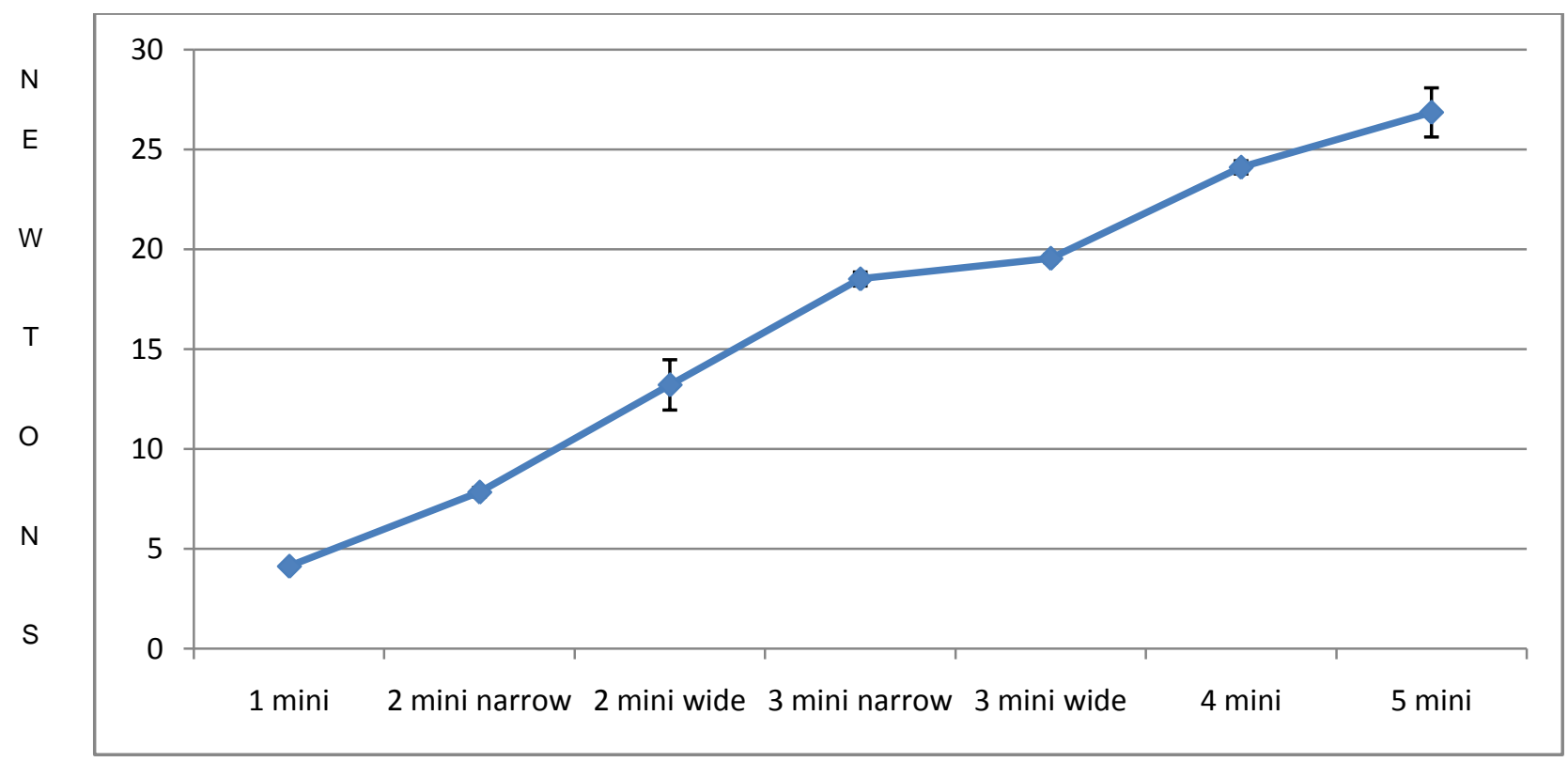

TABLE 2- Summary of 2-way ANOVA for Dislodgement Force

$\begin{array}{ccccc}\text { Source } & \text { DF } & \text { Sum of Squares } & \text { Mean Square } & \text { F Ratio } \\ \text { Model } & 6 & 7339.0552 & 1223.18 & 2322.09 \\ \text { Error } & 120 & 63.2109 & 0.53 & \begin{array}{c}\text { Prob }> \\ \text { F }\end{array} \\ \text { C. Total } & 126 & 7402.2661 & & <.0001\end{array}$


A Tukey-Kramer HSD analysis was also performed and the data set was found to with an Alpha value of 0.05 . The results are contained in Table 3. Those groups which have different letters in the statistical category are shown to have means that are significantly different from one another.

\title{
TABLE 3- Comparison of the Dislodgement Force for Each Group
}

\author{
Statistical Category* \\ Level \\ Mean \\ 5 Mini's \\ A \\ 26.86 \\ 4 Mini's \\ B \\ 24.1 \\ 3 Mini's Wide \\ C \\ 19.54 \\ 3 Mini's Narrow \\ D \\ 18.5 \\ 2 Mini's Wide \\ E \\ 2 Mini's Narrow \\ F \\ 7.84 \\ 1 Mini \\ G \\ 4.13 \\ *Levels not connected by same letter are significantly different. \\ Data was analyzed using a Tukey multiple comparison test.
}

The average load was divided by the number of mini dental implants used for each combination. An ANOVA test was performed to examine the mean load per 
implant. This can be seen in Table 4, which demonstrates that the means for each group are not equal and the actual means for all seven groups can be seen in Table 5 .

\section{Table 4- Summary of 2-way ANOVA for Average Load per Implant}

$\begin{array}{ccccc}\text { Source } & \text { DF } & \begin{array}{c}\text { Sum of } \\ \text { Squares }\end{array} & \begin{array}{c}\text { Mean } \\ \text { Square }\end{array} & \text { F Ratio } \\ \text { Model } & 6 & 121.00695 & 20.1678 & 251.306 \\ \text { Error } & 120 & 9.63026 & 0.0803 & \begin{array}{c}\text { Prob > } \\ \text { F }\end{array} \\ \text { C. Total } & 126 & 130.63721 & & <.0001\end{array}$

Table 5- Distribution of Force per Implant During Dislodgement

$\begin{array}{ccc}\text { Name } & \text { Mean } & \begin{array}{c}\text { Std Dev } \\ \text { 1 Mini }\end{array} \\ 4.13 & 0.148 \\ \text { 2 Mini's Narrow } & 3.92 & 0.118 \\ \text { 2 Mini's Wide } & 6.75 & 0.631 \\ \text { 3 Mini's Narrow } & 6.17 & 0.116 \\ \text { 3 Mini's Wide } & 6.51 & 0.068 \\ \text { 4 Mini's } & 6.03 & 0.082 \\ \text { 5 Mini's } & 5.1 & 1.225\end{array}$

A Tukey-Kramer HSD analysis was performed on the data from Table 4 as well, in order to compare the dislodgement forces for the individual implants in each group. As can be seen in Table 5, the difference in the dislodgment forces for the implants individually was not always significant, as is shown by levels connected by the same 
letter. The 2 mini wide and 3 mini wide groups have a mean differing by only $0.23 \mathrm{~N}$. The 3 mini narrow and the 4 mini groups vary by $0.15 \mathrm{~N}$, and the 1 mini and 2 mini narrow groups by $0.21 \mathrm{~N}$. The 6 mini group was the only level to show a significant difference from all other groups.

\section{Table 6- Comparison for the Dislodgement Force per Implant}

\section{Statistical Category*}

\section{Level}

2 Mini's Wide

3 Mini's Wide

3 Mini's Narrow

4 Mini's

5 Mini's

1 Mini

2 Mini's Narrow
A

A

B

B
Mean

6.75

6.51

6.17

6.03

C

5.37

4.13

3.92

*Levels not connected by same letter are significantly different.

Data was analyzed using a Tukey multiple comparison test

The results from this study on the load to dislodgment force required for the seven mini implant groups along with the ranges of results from the literature on the other various attachment types are compared in Table 7 seen below in descending order. 
Table 7- Reported Forces from Load to Dislodgment Experiments for Different Attachment Systems including: Petropoulos et al 2002, Petropoulos et al 1997, Chung et al, Alsabeeha et al, and Canizales et al.

\begin{tabular}{|c|c|c|c|c|c|}
\hline Type & $\begin{array}{c}\text { Petrop } \\
02\end{array}$ & $\begin{array}{c}\text { Petrop } \\
97\end{array}$ & Chung & Alsabeeha & Canizales \\
\hline ZAAG & 37.2 & & & & \\
\hline ERA gray & & 7.19 & 35.24 & & \\
\hline Locator white & & & 28.95 & 12.39 & \\
\hline Spheroflex ball & & & 27.34 & & \\
\hline 5MDI's & & & & & 26.86 \\
\hline Nobel Ball (Std) & 24.3 & 2.4 & & & \\
\hline Hader Bar & & 20.6 & 24.15 & & \\
\hline 4 MDI's & & & & & 24.1 \\
\hline ERA white & & & 23.76 & & \\
\hline 3 MDI's wide & & & & & 19.54 \\
\hline 3 MDI's narrow & & & & & 18.5 \\
\hline ERA orange & 18.5 & & & & \\
\hline $\begin{array}{c}\text { Nobel Ball } \\
\text { (2.25) }\end{array}$ & 17.8 & & & 17.32 & \\
\hline 2 MDI's wide & & & & & 13.49 \\
\hline Locator pink & & & 12.33 & 9.4 & \\
\hline Zest Anchor & 11.6 & 5.59 & & & \\
\hline 2 MDI's narrow & & & & & 7.84 \\
\hline 1 MDI & & & & & 4.13 \\
\hline Shiner Magnet & & & 3.88 & & \\
\hline Locator Blue & & & & 3.83 & \\
\hline $\begin{array}{c}\text { Magnedisc } \\
\text { Magnet }\end{array}$ & & & 3.69 & & \\
\hline Maxi 2 Magnet & & & 3.68 & & \\
\hline Zest Magnet & & 1.25 & & & \\
\hline
\end{tabular}




\section{Discussion}

The present study investigated the dislodging forces necessary to separate acrylic blocks representing the mandible and a denture when connected by various quantities and arrangements of mini dental implants and housings. The results support the hypothesis in that as the number of implants increased the amount of dislodging forces needed also increased. The null hypothesis, however, was rejected in that the position of the implants when comparing groups with the same number did have an effect of the amount of force needed for dislodgement.

The most commonly used attachment on the market today for two mandibular implants to retain an overdenture is the Locator system by Zest Anchors International. It is reported by Zest that the dislodgment forces necessary to work on locator attachments in increasing order are as follows: Blue/Light Retention-1.5lbs each or 6.672 Newton's, Pink/Medium Retention- 3lbs each or 13.344 Newton's, and White/Heavy Retention- 5lbs each or 22.24 Newton's. When comparing the data from this study to the reported data for locator attachments and their dislodging force when two are used to retain a mandibular denture, the hypothesis is proven to some extent. In order to dislodge two Blue (light retention) caps on locator attachments it requires 13.34 Newton's of force which is comparable to two mini implants if placed in a wide orientation (or in the canine region). The medium retention or Pink caps would require twice the required force of the Blue caps, or 26.68 Newtons for two, which is comparable to five mini dental implants with o-rings at 26.86 Newtons. The variations of 
3 and $4 \mathrm{MDI}$ groups exist between the dislodgement force of the Blue and the Pink caps. The white or heavy retention caps on two locator attachments would require 44.48 Newton's of which would require much more dislodgement force than five mini dental implants with o-rings could provide. This information is presented in Figure 5 below.

Figure 5- Mini Implant Data as Compared to Zest Anchors International Data for 2 Locator Attachments

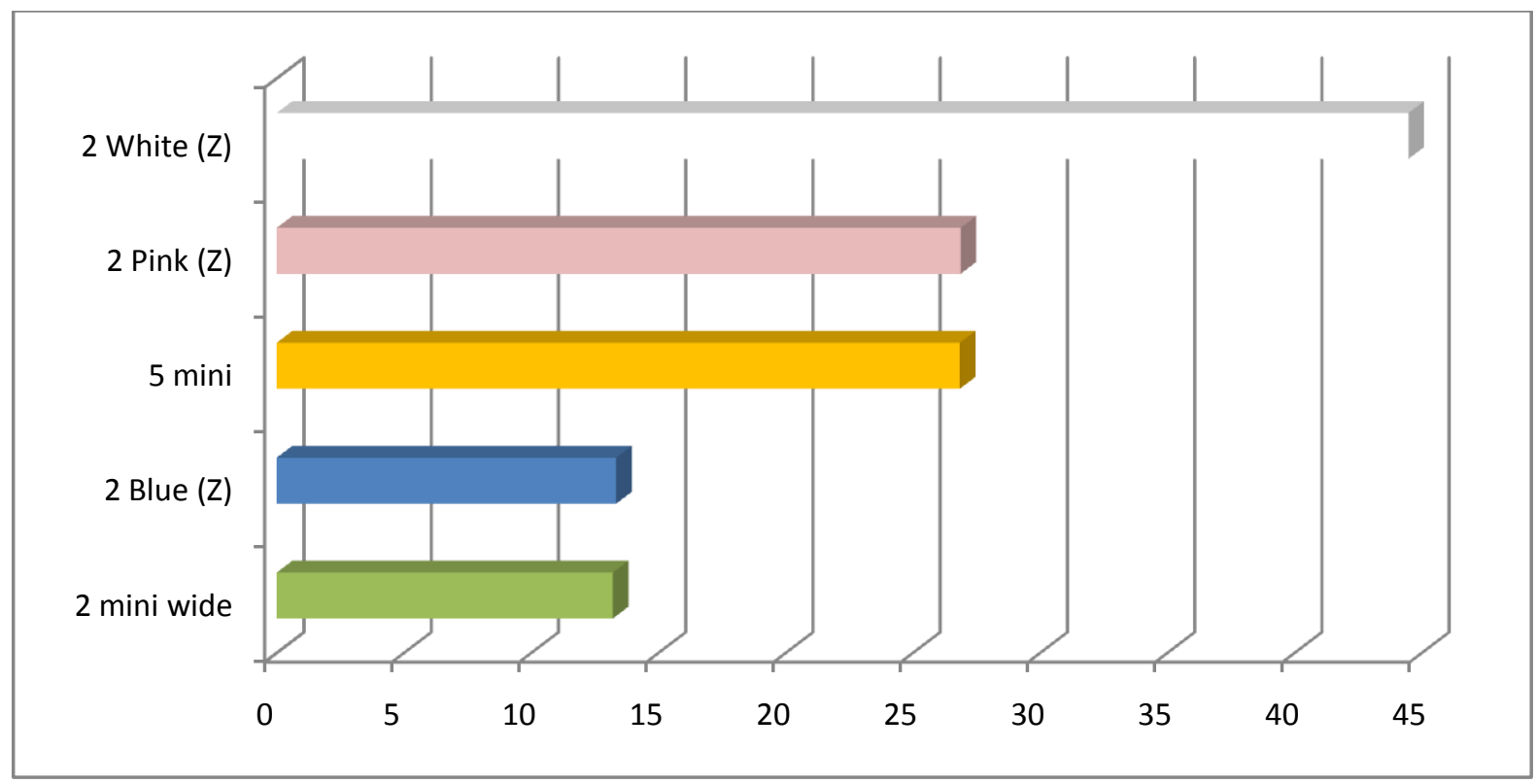

NEWTONS

In a study done by Chung et al in 2004, using a similar technique to measure the retention of two locator attachments with Pink (medium) retention caps, it was found that 12.33 Newton's were needed for dislodgement or $6.165 \mathrm{~N}$ per attachment. This is a little less than half of that reported by Zest Anchors International. Another similar study using the Instron Machine done in 2010 by Alsabeeha et al tested the dislodging forces 
for a single locator attachment with all three retentive caps. The results were as follows: Blue/Light Retention- 3.83N, Pink/Medium Retention- 9.40N, and White/Heavy Retention- 12.39 N. Again, these results show that much less force than reported by the manufacturer is needed to remove locator attachments from their retentive caps. This information would only further support the hypothesis that a certain number of mini dental implants do have a retentive capability that rivals traditional locator systems. This information is compared in Figure 6.

Figure 6- Retention of Mini O-Rings and Locator Attachments as Reported by this study, Zest Anchors International, and Alsabeeha

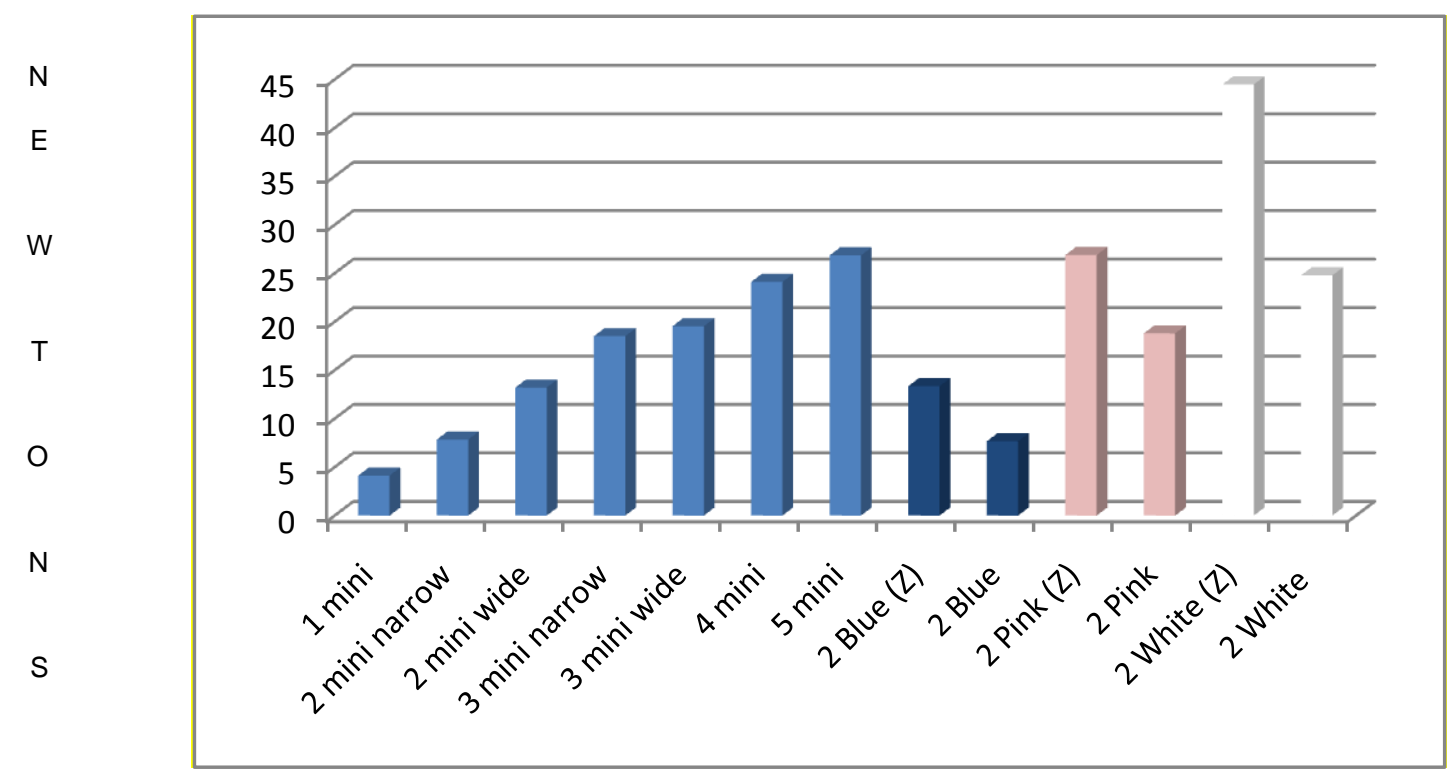

Despite the discrepancy in the data that is reported on the retention to dislodging forces by locator caps, the data from this study continues to support that mini dental implants have the capability to provide adequate retention to a mandibular overdenture when traditional implants are not an option due to anatomical limitations or to financial 
considerations. Further investigation into this topic could include an experiment testing both mini o-rings and locators using the same parameters on the same apparatus to obtain accurate information comparing the different implant systems.

Another parameter that was included in this study was to question if the position of the mini dental implants around the arch had an impact on the amount of retention provided. The results, as seen in Table 5, reveal that the distribution of the force to the individual implants is dependent upon both the number of implants and the location of the implants around the artificial arch as seen within the 2 wide and 2 narrow groups. 2 MDI's in a wide orientation as compared to the two MDI's in a narrow orientation have a mean load per implant of 3.91 and 6.75 Newtons respectively. However, in the 3 mini dental implants groups, both wide and narrow, the center implant seems to have removed the variation in the distribution of load per implant as they have 6.17 and 6.51 Newtown loads per implant. Both of the 3 mini dental implant groups, along with the 2 MDI wide and $4 \mathrm{MDI}$ groups are all seen to have mean load per implant values within less than one Newton of each other. It can be postulated therefore that in order to achieve comparable retention to traditional locator caps with the maximum dislodging force per implant, the mini dental implants need to be placed in a wide orientation, and/or have a centrally located implant. The reason for this discrepancy between the 2MDI groups can be postulated to exist due to reduction of rocking forces by distribution of the implants around the arch.

The data in this study leads to a recommended number of mandibular overdenture MDI's to be four, as five MDl's did not significantly increase the retention from four MDI's. Although the retention of the MDl's seems to be equivalent from this 
study, there remains a lack of documented evidence from prospective trials of the longevity and success rates of mini dental implants.

\section{CHAPTER V}

\section{Summary}

This study attempted to provide information on the retention to dislodgement capabilities of the mini dental implant system. It provides data for only one manufacturer and is limited in that it does not include recordings of the locator attachments in the same testing sample. The data provided, however, does inform the practitioner of the ability of the mini dental implant with o-ring to retain a mandibular overdenture for patients who are not candidates for traditional implants systems. Mini dental implants, when indicated, can be an alternative to retaining a mandibular denture that is easily dislodged by the tongue and other oral structures. Patients who receive this treatment modality can truly increase their chewing capability, their confidence and often times their health with the help of a mini dental implant overdenture.

\section{Conclusions}

1. Mini Dental Implant Overdentures are an acceptable alternative when traditional implants are not indicated.

2. The data in this study leads to a recommended number of mandibular overdenture mini dental implants to be four, as five did not significantly increase the retention.

3. Position affected the amount of retention only when using two mini dental implants, in which case a wide orientation was more retentive. 


\section{Reference List}

Ahn, M. R., et al. "Immediate loading with mini dental implants in the fully edentulous mandible." Implant.Dent. 13.4 (2004): 367-72.

Allen PF, Thomason JM, Jepson NJA, Nohl F, Smith DG and Ellis J. "A Randomized Controlled Trial of Implant-retained Mandibular Overdentures." Journal of Dental Research. 85.6 (2006): 547-51.

Allum, S. R., R. A. Tomlinson, and R. Joshi. "The impact of loads on standard diameter, small diameter and mini implants: a comparative laboratory study." $\underline{\text { Clin.Oral }}$ Implants.Res. 19.6 (2008): 553-59.

Alsabeeha N, Atieh M, Swain MV, and Payne AG. "Attachment systems for manibular single-implant overdentures: an in vitro retention force investigation on different designs." Int.J.Prosthodont. 23.6 (2010): 160-66.

Al-Zubeidi MI, Alsabeeha NH, Thomson WM and Payne AG. "Patient Satisfaction and Dissatisfaction with Mandibular Two-Implant Overdentures Using Different Attachment Systems: 5-Year Outcomes. Clin. Implant Dent. Relat. Res. (Dec 17, 2010).

Balkin B, Steflik DE, and Naval F. "Mini-Dental Implant Insertion with the Auto-Advance Technique for Ongoing Applications." Journal of Oral Implantology. 27.1 (2001): 32-7. 
Block, MS. "Surgery of the Anterior Mandible." 1 ed. Saunders, 2001. 3-33.

Bulard RA, and Vance JB. "Multi-clinic evaluation using mini-dental implants for longterm denture stabilization: a preliminary biometric evaluation." $\underline{\text { Compend Contin }}$ Educ Dent. 26.12 (2005) 892-7.

Christensen GJ. "The 'mini'-implant has arrived." J Am Dent Assoc. 137.3 (2006): 38790.

Chung KH, Chung CY, Cagna DR, and Cronin RJ Jr. " Retention characteristics of attachment systems for implant overdentures." J Prosthodont. 13.4 (2004): 221 6.

de Freitas Borges T, Alves Mendes F, Rezende Carvalho De Oliveira T, Jesus do Prodo C, Domingues das Neves F. "Overdenture with immediate load: mastication and nutrition." Br. J. Nutr. 105.4 (2011): 990-4.

Dilek, O., E. Tezulas, and M. Dincel. "Required minimum primary stability and torque values for immediate loading of mini dental implants: an experimental study in nonviable bovine femoral bone." Oral Surg.Oral Med.Oral Pathol.Oral Radiol.Endod. 105.2 (2008): e20-e27.

Dilek, O. C. and E. Tezulas. "Treatment of a narrow, single tooth edentulous area with mini-dental implants: a clinical report." Oral Surg.Oral Med.Oral Pathol.Oral Radiol.Endod. 103.2 (2007): e22-e25. 
Doukas D, Michelinakis G, Smith PW and Barclay CW. "The influence of interimplant distance and attachment type on the retention characteristics of mandibular overdentures on 2 implants: 6-month fatigue retention values." Int. J. Prosthdont. $21.2(2008): 152-4$.

Doundoulakis JH, Eckert SE, Lidnquist CC and Jeffcoat MK. "The implant-supported overdenture as an alternative to the complete mandibular denture." J. Am. Dent. Assoc. 134.11 (2003): 1455-58.

Fagan, MJ. "History of Dental Implants." Implant Prosthodontics. 1 ed. Year Book Medical Publishers, 1990. 3-9.

---. "The Fagan Endosseus Implant: Surgical and Prosthetic Technique." Implant Prosthodontics. 1 ed. Year Book Medical Publishers, 1990. 61-71.

---. "The Subperiosteal Implant: Surgical and Prosthetic Techniques." Implant Prosthodonitcs. 1 ed. Year Book Medical Publishers, 1990. 139-61.

Felton DA. "Edentulism and Comorbid Factors." J. Prosthodont. 18.2 (2009): 88-96.

Fiore PM, Tam L, Thai HT, Hittleman E and Norman RG. "Retention of Teeth Versus Extraction and Implant Placement: Treatment Preferences of Dental Faculty and Dental Students." J Dent Educ. 72.3 (2008): 352-8.

Griffitts, T. M., C. P. Collins, and P. C. Collins. "Mini dental implants: an adjunct for retention, stability, and comfort for the edentulous patient." Oral Surg.Oral Med.Oral Pathol.Oral Radiol.Endod. 100.5 (2005): e81-e84. 
Jofre J, Hamada T, Nishimura M and Klattenhoff C. "The effects of maximum bite force on marginal bone loss of mini-implants supporting a mandibular overdenture: a randomized controlled trial." Clin. Oral Implants Res. 21.2 (2010): 243-9.

Klemetti E. "Is there a certain number of implants needed to retain an overdenture?" $\mathrm{J}$. Oral Rehabil. 35.1 (2008): 80-4.

Michelinakis G, Barclay CW, and Smith PW. "The influence of interimplant distance and attachment type of the retention characteristics of mandibular overdentures on 2 implants: initial retention values." Int. J. Prosthodont. 19.5 (2006): 507-12.

Misch, Carl E. "An Implant Is Not a Tooth: A Comparison of Peridontal Indexes." Dental Implant Prosthetics. 1 ed. Mosby, 2005. 18-31.

---. "Available Bone and Implant Dentistry." Dental Implant Prosthetics. 1 ed. Mosby, 2005. 105-29.

---. "Generic Root Form Component Terminology." Dental Implant Prosthetics. 1 ed. Mosby, 2005. 32-42.

---. "Rational for Denta Implants." Dental Implant Prosthetics. 1 ed. Mosby, 2005. 1-17.

---. "Treatment Options for Mandibular Implant Overdentures: An Organized Approach." Dental Implant Prosthetics. 1 ed. Mosby, 2005. 206-27.

Naert, I., G. Alsaadi, and M. Quirynen. "Prosthetic aspects and patient satisfaction with two-implant-retained mandibular overdentures: a 10-year randomized clinical study." Int.J.Prosthodont. 17.4 (2004): 401-10. 
Nazarian, A. "Mini dental implants: immediate gratification for patient and provider." Dent.Today 24.10 (2005): 110, 112.

Petropoulos VC, Smith W, Kousvelari E. "Comparison of retention and release periods for implant overdenture attachments." Int. J. Oral Maxillofac. Implants. 12.2 (1997): 176-85.

Petropoulos VC, Smith W. "Maximum dislodging forces of implant overdenture stud attachments." Int.J.Prosthodont. 17.4 (2002): 526-35.

Pietrokovski, J., J. Harfin, and F. Levy. "The influence of age and denture wear on the size of edentulous structures." Gerodontology. 20.2 (2003): 100-05.

Pigozzo MN, Mesquita MF, Henriques GE, Vaz LG. "The service life of implant-retained overdenture attachment systems." J Prosthodont. 102.2 (2009): 74-80.

Preoteasa E, Melescanu-Imre M, Preoteasa CT, Marin M, Lerner H. "Aspects of oral morphology as decision factors in mini-implant supported overdenture." Rom. J.Morphol. Embryol. 51.2 (2010): 309-14.

Rahn, AO. "Educating the Patient." Textbook of Complete Dentures. 5 ed. Lea \& Febiger, 1993. 121-29.

---. "Tooth Supported Complete Denture." Textbook of Complete Dentures. 5 ed. Lea \& Febiger, 1993. 493-512.

Saha S and Ray-Chaudhuri A. "Mandibualr implant-retained compete overdenture using retentive abutments: a case report." Dent. Update. 36.3 (2009): 154-8. 
Shatkin TE, Shatkin S, Oppenheimer BD, and Oppenheimer AJ. "Mini Dental Implants for Long-Term Fixed and Removable Prosthetics: A Retrospective Analysis of 2514 Implants Placed Over a Five-Year Period." Compendium. 28.2 (2007): 92100.

Super T, American Consolidated Mfg. Co., W. Conshohocken, PA

Svetize CA, Bodereau EF Jr. "Comparative study of retentive anchor systems for overdentures." Quintessence Int. 35.6 (2004): 443-8.

van der Bilt A, Burgers M, van Kampen FM, Cune MS. "Mandibular implant-supported overdentures and oral function." Clin. Oral Implants Res. 21.11 (2010): 1209-13. van Kampen FMC, van der Bilt A, Cune MS and Bosman F. "The Influence of Various Attachment Types in Mandibular implant-retained Overdentures on Maxium Bite Force and EMG." Journal of Dental Research. 81.3 (2002): 170-3.

Zest Anchors International

Zwerger, S., M. H. Abu-Id, and T. Kreusch. "[Long-term results of fittig subperiosteal implants: report of twelve patient cases]." Mund Kiefer Gesichtschir. 11.6 (2007): $359-62$. 


\section{CURRICULM VITAE}

Name:

Date of Birth:

Place of Birth:

\section{Education:}

August 2000- 2004

Wheeling Jesuit University

Wheeling, WV

Bachelor of Science- Biology

August 2004-2008

West Virginia University

School of Dentistry

Morgantown, West Virginia

Doctorate of Dental Surgery

July 2008 - present

West Virginia University

School of Dentistry

Department of Graduate Prosthodontics

Morgantown, West Virginia

Master of Science- Prosthodontics
Amanda McPherson Canizales, D.D.S

1982

East Liverpool, $\mathrm{OH}$ 